DOI: https://doi.org/10.47405/mjssh.v6i1.605

\begin{tabular}{|c|c|}
\hline & Malaysian Journal of Social Sciences and Humanities (MJSSH) \\
\hline Malaysian Journal of & Volume 6, Issue 1, January 2021 \\
\hline $\begin{array}{l}\text { Humanities } \\
\text { (mJ-sst) }\end{array}$ & e-ISSN : 2504-8562 \\
\hline & $\begin{array}{l}\text { Journal home page: } \\
\text { www.msocialsciences.com }\end{array}$ \\
\hline
\end{tabular}

\title{
Tahap Kepuasan Pekerja di Sektor Awam Terhadap Latihan Secara Atas Talian Mendepani Pandemik COVID-19 di Malaysia
}

\author{
Mohd Safix Lamsah', Rosniza Aznie Che Rose', Rogis Baker² \\ ${ }^{1}$ Fakulti Sains Sosial dan Kemanusiaan, Universiti Kebangsaan Malaysia (UKM) \\ ${ }^{2}$ Fakulti Pengajian dan Pengurusan Pertahanan, Universiti Pertahanan Nasional Malaysia (UPNM) \\ Correspondence: Mohd Safix Lamsah (abumushtarique@gmail.com)
}

\begin{abstract}
Abstrak
Latihan di tempat kerja merupakan faktor kritikal dalam meningkatkan kekuatan sumber manusia khususnya membentuk prestasi kerja yang optimis. Pengurusan latihan yang baik dan kreatif akan mempengaruhi kuantiti penyertaan dan tahap kepuasan daripada peserta. Walau bagaimanapun, pengurusan latihan secara atas talian di kebanyakan organisasi secara umumnya masih berada pada tahap yang rendah mendepani situasi sukar pandemik COVID-19. Sehubungan dengan itu, kajian yang dijalankan ini adalah berkenaan pengurusan latihan secara atas talian di Kementerian Pertahanan, Malaysia dalam konteks penerimaan peserta latihan. Terdapat tiga objektif dalam kajian ini iaitu mengenalpasti profil peserta latihan, menganalisis tahap kepuasan peserta terhadap latihan secara atas talian dan mencadangkan langkah penambahbaikan terhadap pengurusan latihan secara atas talian di sektor awam. Kaedah kajian yang digunakan adalah pemerhatian, temu bual tidak rasmi dan borang soal selidik yang diedarkan kepada 210 orang responden. Pemilihan sampel dilakukan menggunakan formula Taro Yamanae. Data kajian dianalisis menggunakan analisis deskriptif frekuensi, CrossTabulation, Chi-Square dan analisis kolerasi menggunakan perisian Statistical Package for Social Sciences. Berdasarkan hasil kajian, didapati bahawa penyertaan peserta latihan secara atas talian disebabkan oleh faktor platform atas talian yang mudah untuk diakses, modul latihan secara atas talian yang interaktif, rakaman video latihan yang boleh dijadikan rujukan dan suasana latihan yang fleksibel di mana nilai min yang diperolehi adalah tinggi. Secara keseluruhan, tahap kepuasan responden terhadap pengurusan latihan secara atas talian adalah pada tahap sederhana. Oleh yang demikian, setiap latihan secara atas talian perlu diuruskan dengan dengan efisyen dari segenap aspek agar impaknya menjamin kepuasan dan keperluan pekerja.
\end{abstract}

Kata kunci: COVID-19, latihan atas talian, modul latihan, pengurusan latihan, sektor awam

\section{The Level of Satisfaction of Employees in the Public Sector on Online During Pandemic COVID-19 in Malaysia}

\begin{abstract}
Training in the workplace is a critical factor in increasing the strength of human resources, especially in shaping optimistic work performance. Good and creative training management will influence the quantity of participation and the level of satisfaction of the participants. However, online training management in most organizations in general is still at a low level facing the difficult situation of the COVID-19 pandemic. In this regard, this study is about online training management in the Ministry of Defense, Malaysia in the context of the acceptance of training participants. There are three objectives
\end{abstract}


in this study which is to identify the profile of training participants, analyze the level of satisfaction of participants with online training and suggest measures to improve online training management in the public sector. The research methods used were observations, informal interviews and questionnaires distributed to 210 respondents. Sample selection was done using the Taro Yamanae formula. Study data were analyzed using frequency descriptive analysis, Cross-Tabulation, Chi-Square and correlation analysis using Statistical Package for Social Sciences software. Based on the results of the study, it was found that the participation of online training participants is due to the participants making it easier to interact with speakers, interactive online training modules, playable training video recordings and flexible training venues where the mean value obtained is high. Overall, the level of respondents' satisfaction with online training management is at a moderate level. Therefore, every online training needs to be managed efficiently from all aspects so that the impact guarantees employee satisfaction and needs.

Keywords: COVID-19, online training, training module, training management, public sector

\section{Pengenalan}

Pandemik COVID-19 merupakan wabak penyakit Koronavirus 2019 yang sedang melanda seluruh dunia ketika ini. Wabak yang mula dikesan seawal Disember 2019 telah mencecah angka 51 juta kes dan jumlah kematian sebanyak 1.2 juta mangsa sehingga November 2020. Malah, kes ini dijangka terus meningkat dari semasa ke semasa. Rentetan itu, kerajaan Malaysia telah melaksanakan langkah proaktif bagi mengekang penularan virus ini seperti melaksanakan Perintah Kawalan Pergerakan (PKP), mengehadkan pergerakan ke luar rumah, mengimplementasikan bekerja dari rumah (Work From Home) dan penyesuaian diri dengan norma baharu. Namun begitu, pendekatan yang diambil ini telah menyebabkan pelbagai masalah yang wujud dalam kalangan pekerja khususnya di sektor kerajaan yang memberi fokus kepada Kementerian Pertahanan, Malaysia. Keadaan ini boleh dilihat melalui perubahan khususnya dalam aspek pengurusan latihan yang dijalankan di kementerian tersebut. Justeru, pengurusan latihan ketika mendepani pandemik COVID-19 adalah sangat penting dan mencabar kerana memerlukan teknik latihan yang lebih praktikal termasuklah penglibatan positif dalam kalangan pekerja dan pihak pengurusan atasan.

Pengurusan latihan merupakan pendekatan yang dilakukan oleh organisasi untuk meningkatkan kemampuan pekerja dalam melaksanakan tugas atau memainkan peranan yang telah ditetapkan organisasi (Helton et al., 2019). Latihan tertumpu kepada usaha menyediakan pekerja secara khusus bagi tugas yang telah diberikan dan berorientasikan masa kini. Secara umumnya, latihan adalah proses pekerja untuk belajar dalam mendapatkan pengetahuan, kemahiran dan nilai yang diperlukan untuk melaksanakan tugas-tugas dengan efektif (Iqbal, 2018). Cabaran globalisasi yang semakin bertambah mendepani pandemik COVID-19 memerlukan usaha yang gigih dalam mencetuskan pembangunan sumber manusia. Tanggungjawab ke arah memperkasakan ilmu, kepakaran dan kemahiran pekerja adalah matlamat utama yang perlu diberi penekanan. Maka, latihan yang bertepatan dengan misi, visi dan objektif khususnya secara atas talian perlu dijadikan indikator penting untuk menyusun semula pendekatan latihan yang boleh diamalkan oleh organisasi bagi mencapai impak yang ditetapkan.

Kementerian Pertahanan, Malaysia adalah antara kementerian yang terpenting di negara ini. Sumber manusia yang mempunyai pelbagai latar belakang pekerja seperti pekerja awam dan tentera dalam organisasi yang sama menggalakkan kesepaduan dan kerjasama yang efektif. Cawangan Latihan, Bahagian Pengurusan Sumber Manusia (BPSM) merupakan organisasi yang terlibat dalam merangka modul latihan, melaksanakan latihan dan menilai latihan yang telah dijalankan di kementerian ini. Namun begitu, Cawangan Latihan telah mengalami beberapa kesukaran dari segi penyediaan latihan secara atas talian sepanjang pandemik COVID-19 dan mempunyai kekangan terhadap kuantiti dan kualiti modul latihan. Menurut BPSM Kementerian Pertahanan, Malaysia, kebanyakan modul latihan seperti ceramah (executive talk) terpaksa ditukar secara atas talian rentetan bagi menjaga jarak sosial (social distancing) antara pekerja. Malah, latihan yang melibatkan modul seperti pembinaan kumpulan 
dalam kalangan pekerja awam dan tentera (team building) terpaksa di tangguhkan buat sementara waktu. Walau bagaimanapun, latihan di kementerian ini wajib dilaksanankan selaras dengan penyertaan selama tujuh hari setahun seperti yang telah termaktub dalam Pekeliling Perkhidmatan Bil. 6 Tahun 2005 dalam Dasar Latihan Sumber Manusia Sektor Awam. Oleh itu, pemilihan teknik latihan yang terbaik antaranya melalui pendekatan latihan secara atas talian amat signifikan bagi mengelakkan penularan wabak yang semakin membimbangkan di samping menjadikan pendekatan ini sebagai norma baharu dalam meningkatkan prestasi pekerja.

\section{Sorotan Literatur}

\section{Perkembangan pembangunan dan pengurusan latihan sektor awam di Malaysia}

Pembangunan dan pengurusan latihan seringkali dianggap sebagai isu yang kritikal dalam bidang pengurusan sumber manusia profesional (Noor Azmi et al., 2015). Latihan yang dilaksanakan adalah untuk melengkapi segenap aspek kepada staf atasan, pertengahan dan rendah. Tujuan pelaksanaan latihan berupaya meningkatkan pengetahuan penting, kemahiran terkini, kebolehan baharu, sikap positif dan apa jua keperluan semasa yang relevan supaya mereka berupaya meningkatkan daya saing diri, mengurus peluang dan masalah dengan bijaksana serta memberi respons yang segera terhadap pelbagai cabaran dalam persekitaran organisasi secara berterusan (Hald et al., 2018). Terdapat banyak bukti yang menyokong sumbangan pembangunan dan pengurusan latihan terhadap kemajuan pekerja dan organisasi. Kajian tentang 'Global Leadership Forecast' 2008/2009 telah dilaksanakan oleh Dimensi Pembangunan Antarabangsa mendapati bahawa, 41 peratus daripada pengurus dunia yang mempunyai prestasi yang baik adalah dalam kalangan yang telah melalui latihan kepimpinan Russel et al., (2018). Malah, turut disokong oleh kajian tentang latihan pembangunan kepimpinan kepada staf pentadbiran oleh Taylor et al., (2019) yang membuktikan bahawa, latihan berupaya mencipta momentum bagi menghadapi perubahan yang dinamik dan meningkatkan keberkesanan organisasi. Tambahan pula, masih terdapat banyak kajian di Malaysia yang membuktikan keberkesanan latihan membentuk prestasi pekerja sejak dahulu lagi.

Perkembangan pembangunan dan pengurusan latihan sektor awam di Malaysia banyak dikaitkan dengan sejarah lampau seawal tahun 1920-an. Pengurusan latihan yang terbahagi kepada beberapa bidang latihan atau sektor dipecahkan kepada beberapa bidang seperti bidang pengurusan dan pentadbiran, kepolisan, ketenteraan, perguruan, vokasional, pertanian dan bidang-bidang lain. Latihan dalam bidang pengurusan dan pentadbiran telah diberi penekanan sejak zaman penjajahan Belanda, Portugis dan British. Pada tahun 1920-an sehingga 1930-an, bakal-bakal pegawai terutama di peringkat daerah telah diberi latihan pra-perkhidmatan di Kolej Melayu Kuala Kangsar (MCKK), manakala bakalbakal pegawai lain yang ingin memasuki Perkhidmatan Awam Tanah Melayu (Malayan Civil Service) diberi latihan di pejabat tanah jajahan di England (INTAN, 1972).

Setelah Tanah Melayu mencapai kemerdekaan pada tahun 1957, peluang latihan terbuka dengan lebih luas apabila pegawai Perkhidmatan Pengurusan Melayu (Malay Administrative Service) berpeluang untuk memasuki Perkhidmatan Awam Tanah Melayu. Maka, penekanan untuk mengeluarkan satu laporan kajian tentang keperluan tenaga manusia telah dilaksanakan pada tahun 1969. Laporan ini mengesyorkan agar menubuhkan sebuah institusi jitu yang berorientasikan pembangunan untuk memberi latihan pengurusan kepada pegawai di semua peringkat dalam pentadbiran semua agensi kerajaan. Hasil daripada laporan ini, maka kerajaan telah menubuhkan Institut Tadbiran Awam Negara (INTAN) pada September 1972. INTAN berperanan sebagai sebuah institusi latihan yang pesat di Malaysia di samping kerajaan telah membentuk satu dasar untuk menyelaras kegiatan latihan di semua peringkat.

Seterusnya, program latihan pentadbiran dan pengurusan sektor awam terus dikaji dan diperkemaskan untuk meningkatkan kecekapan dan daya pengeluaran. Pada tahun 1981 hingga 1985, pelbagai usaha telah diambil oleh kerajaan untuk menghantar kakitangan kerajaan daripada semua bidang pekerjaan untuk mengikuti kursus ijazah lanjutan. Dalam tempoh Rancangan Malaysia Keempat (RMK-4), kirakira 4600 pegawai di sektor awam telah menyertai skim latihan tersebut. Di samping itu, pegawai yang 
berkhidmat di sektor awam juga berpeluang untuk ditempatkan di sektor swasta bagi mendapatkan pengalaman korporat ketika itu.

Sehingga hari ini, perkembangan pembangunan dan pengurusan latihan sektor awam di Malaysia semakin diambil perhatian melalui Kementerian Sumber Manusia yang telah mewujudkan penambahbaikan melalui Dasar Latihan Sumber Manusia Sektor Awam PP Bil.06/2005. Latihan yang terdapat di organisasi turut dipelbagaikan bagi menarik minat peserta untuk menghadiri latihan di samping menetapkan jumlah latihan dalam setahun yang perlu dihadiri oleh setiap pekerja. Oleh yang demikian, langkah-langkah strategik yang ambil oleh kerajaan bagi menambah mutu latihan dalam memperkasakan prestasi pekerja di sektor awam telah memberi impak yang positif. Tanpa perkembangan pembangunan dan pengurusan latihan sektor awam di Malaysia, maka latihan yang dilaksanakan tidak akan memberi hasil khususnya dalam melahirkan pekerja yang berupaya melaksanakan bidang tugas dengan baik seperti yang disarankan oleh kerajaan dalam Dasar Pembangunan Organisasi.

\section{Penggunaan teknologi maklumat dan komunikasi (ICT) dalam kalangan individu di Malaysia}

Teknologi merupakan medium perkembangan elektronik yang semakin mengubah corak kehidupan manusia dan mempengaruhi terutamanya dalam dunia pekerjaan. Hal ini demikian kerana, penggunaan teknologi dalam organisasi dapat membantu dalam meningkatkan prestasi pekerja berbanding hanya bergantung kepada tenaga kerja primitif (Stirpe, 2017). Kebiasaannya, teknologi sering dianggap sebuah alat yang berfungsi untuk meningkatkan hasil produk seperti penggunaan robot. Tetapi, teknologi turut dikategorikan sebagai sistem informasi dan multimedia seperti komputer, internet, jalur lebar dan laman sosial yang dicipta untuk memudahkan dalam dunia pekerjaan dan mampu meningkatkan produktiviti sebuah organisasi (Van Thielen et al., 2017). Oleh sebab itu, penggunaan teknologi semakin dipraktikkan kerana kekurangan ralat, cepat dan relevan.

Mendepani era digital menurut Yuen (2018), penggunaan teknologi maklumat dan komunikasi atau 'Information and Communications Technology' (ICT) telah memberi peluang kepada setiap individu khususnya dalam kalangan pekerja untuk belajar dan mengaplikasi kemahiran-kemahiran yang diperlukan di alaf 21. Mackay (2017) menyatakan, tanpa pengetahuan dan kemahiran berkaitan ICT, seseorang individu agak sukar untuk bersaing dalam dunia moden ketika ini. Hal ini demikian kerana, keperluan pekerjaan akan berubah-berubah dan pekerja perlu mengembangkan kemahiran serta kecekapan yang diperlukan oleh setiap organisasi.

Berdasarkan kajian yang dijalankan oleh He et al. (2019), beliau menyatakan bahawa, penggunaan dan peranan teknologi komunikasi yang telah menyumbang kepada proses komunikasi yang berkesan dalam organisasi. Kajian ini turut menyimpulkan apabila sesebuah organisasi yang cekap menggunakan ICT, maka lebih cepat untuk mencapai objektif dan mampu memberi daya saing kepada organisasi lain. Penggunaan ICT dalam organisasi bukan lagi suatu yang asing, malah memudahkan interaksi antara sesama kakitangan dalam organisasi dan turut digunakan sebagai perantara dalam menyampaikan maklumat serta membantu melancarkan tugasan dalam organisasi. Penyataan ini disokong oleh Ronen (2017), yang menyatakan pekerja yang mempunyai kemahiran yang luas dalam ICT telah membantu meningkatkan prestasi kendiri dan organisasi tersebut. Di samping itu, organisasi yang menggunakan ICT telah menyebabkan berlaku peningkatan pekerja yang kurang mahir dalam kalangan pekerja senior. Malah, kemahiran kerja mereka turut menurun sehingga mempengaruhi kualiti dan produktiviti dalam organisasi. Oleh yang demikian, penggunaan ICT dalam organisasi secara meluas perlu disokong oleh setiap pekerja agar kebaikan dalam meningkatkan prestasi pekerja dapat dicapai. Bagi meningkatkan penggunaan ICT dalam kalangan pekerja, organisasi itu perlu memberi latihan yang holistik agar setiap pekerja tidak tertinggal dalam menggunakan teknologi yang sedia ada.

Statistik penggunaan ICT oleh individu di Malaysia berdasarkan Jabatan Perangkaan Malaysia pada tahun 2018 dan tahun 2019 menunjukkan peningkatan peratusan penggunaan internet iaitu sebanyak 3 peratus daripada 81.2 peratus pada tahun 2018 kepada 84.2 peratus pada tahun 2019. Peratusan bagi penggunaan komputer juga menunjukkan peningkatan sebanyak 1.6 peratus daripada 70.5 peratus pada 
tahun 2018 kepada 72.1 peratus pada tahun 2019. Namun begitu, penggunaan telefon bimbit oleh individu masih kekal sebanyak 97.9 peratus pada tahun 2018 dan 2019. Statistik ini dikeluarkan daripada Laporan Survei Penggunaan dan Capaian ICT oleh Individu dan Isi Rumah 2019. Berdasarkan laporan tersebut jelas menunjukkan bahawa, sekurang-kurangnya 70 peratus individu di Malaysia menggunakan ICT dalam kehidupan mereka sama ada menggunakan internet, komputer atau telefon bimbit. Oleh yang demikian, latihan secara atas talian adalah medium yang terbaik untuk memastikan kesinambungan proses pembelajaran sewaktu pandemik COVID-19 yang melanda negara. Justeru, penggunaan ICT yang semakin meluas digunakan dalam organisasi dilihat bertambah relevan seterusnya mampu untuk berdaya saing dengan organisasi lain.

\section{Masalah pengurusan latihan secaraatas talian sektor awam di Malaysia}

Umum mengetahui bahawa pengurusan latihan secara atas talian yang menarik amat penting dalam menjadikan konsep penyampaian dan maklumat lebih efisien menggunakan ICT. Maka, penyediaan modul, slot dan aktiviti secara atas talian perlu lebih kreatif berbanding menggunakan bahan latihan secara konvensional dalam mewujudkan suasana latihan yang interaktif. Pengurusan latihan secara atas talian yang terdapat di sektor-sektor awam merupakan seliaan Bahagian Pengurusan Sumber Manusia di setiap kementerian. Dalam kajian ini, latihan alam maya yang dijalankan kepada setiap kakitangan di Kementerian Pertahanan, Malaysia merupakan seliaan pihak Cawangan Latihan. Organisasi ini bertindak dalam merangka, menjalankan, menguruskan dan menilai latihan secara atas talian agar mempunyai impak yang baik di samping sentiasa mencari alternatif penggunaan platform yang sesuai seperti 'Google Meet', 'Webinar', 'Microsoft Support Team', 'Youtube Live', 'Facebook Live' dan sebagainya.

Berdasarkan kajian Padlee et al., (2019), untuk mendapatkan capaian internet berkelajuan tinggi dan stabil di sebilangan tempat masih kurang memuaskan. Hal ini disebabkan kebanyakan pekerja bukan sahaja tinggal di kawasan perumahan yang mempunyai liputan internet yang bagus, tetapi terdapat juga sebilangan pekerja yang tinggal di pinggir-pinggir bandar yang kurang menikmati capaian internet seperti yang diharapkan. Malah, latihan yang dijalankan secara atas talian menyebabkan penyampaian penceramah menjadi tersekat-sekat dan tidak jelas akibat talian internet yang tidak stabil. Impaknya, ilmu selepas latihan tidak dapat dipraktikkan, malah lebih membimbangkan apabila terdapat peserta latihan yang tidak faham akibat gangguan teknikal sepanjang menyertai latihan secara atas talian. Masalah kemerosotan capaian internet di sebilangan tempat memerlukan lebih banyak liputan internet yang stabil ketika mendepani cabaran pandemik COVID-19 sekaligus menjadi dilema dalam kalangan pekerja untuk menyertai latihan secara atas talian (Arawati Agus, 2015).

Dilihat dari perspektif berbeza, terdapat juga masalah lain yang dihadapi dalam menguruskan latihan secara atas talian iaitu suasana pembelajaran peserta yang tidak kondusif untuk menyertai latihan. Mackay (2017) menyatakan, latihan yang disertai telah diganggu oleh faktor keadaan semasa peserta seperti menjaga anak, bunyi bising disebabkan jiran-jiran, keadaan rumah yang mempunyai ramai ahli keluarga dan sebagainya. Masalah lain yang turut dihadapi apabila ahli keluarga yang tidak memahami keadaan dan tidak memberi sokongan moral semasa peserta mengikuti latihan secara atas talian. Hal ini demikian kerana, mereka dianggap melakukan perkara yang tidak berfaedah kerana berjam-jam melihat laptop (Pfister et al., 2017). Penyataan ini disokong oleh kajian yang dilakukan oleh Ronen (2017), bahawa isteri akan dimarahi oleh suami akibat terlalu fokus dengan hal kerja sewaktu bekerja dari rumah (WFH) sedangkan waktu tersebut adalah waktu hakiki bekerja. Hal ini amat bertentangan dengan usaha mengimplementasikan latihan secara atas talian mendepani pandemik COVID-19. Oleh itu, persekitaran seseorang itu perlu diuruskan dengan baik seperti mencari lokasi yang bersesuaian di samping menjelaskan kepada ahli keluarga terhadap latihan yang disertai secara atas talian.

Menurut Helton et al. (2019), topik latihan yang kurang berkaitan dengan isu semasa, kurang kesesuaian latihan dengan bidang tugas, penyampaian penceramah yang lemah dan kurang kreativiti modul semasa latihan menyebabkan pengurusan latihan secara atas talian di sektor awam mengalami tahap yang kurang memuaskan. Pelaksanaan latihan ini merupakan syarat untuk melengkapkan jumlah jam latihan bagi setiap pekerja tetapi kurang menyedari terhadap kepentingan utama latihan untuk meningkatkan prestasi pekerja. Impaknya, peserta akan mengalami bosan dan tidak berminat untuk menyertai latihan 
tersebut dan menganggap latihan secara atas talian adalah suatu acara yang remeh. Di samping itu, latihan secara atas talian juga dianggap kurang mengaplikasikan teknologi dengan baik (Saliba de Oliveira, 2018). Hal ini disebabkan penganjur latihan dan penceramah tidak memasukkan elemen interaktif ketika latihan dijalankan seperti mengikuti kuiz selepas latihan. Kesannya, peserta latihan kurang memberikan fokus yang sebaiknya kerana apabila latihan telah tamat, maka slot latihan tersebut berakhir tanpa aktiviti susulan.

\section{Metod kajian}

Sampel kajian yang dipilih merupakan kakitangan di Kementerian Pertahanan, Malaysia yang menyertai latihan secara atas talian sejak Mac 2020 iaitu bermulanya Perintah Kawalan Pergerakan (PKP) sehingga Oktober 2020 iaitu Perintah Kawalan Pergerakan Bersyarat (PKPB). Durasi masa ini yang berdasarkan saranan kerajaan untuk bekerja dari rumah (WFH). Pemilihan responden adalah menggunakan teknik persampelan bertujuan berdasarkan ciri-ciri yang telah ditetapkan oleh pengkaji mengikut objektif kajian. Berdasarkan hasil temu bual bersama salah seorang pegawai di Cawangan Latihan, Bahagian Pengurusan Sumber Manusia Kementerian Pertahanan, Malaysia iaitu Encik Mohd Yusri Ab Ghani, jumlah peserta yang menyertai latihan secara atas talian sepanjang tempoh tersebut seramai kira-kira 400 orang. Data bagi jumlah tersebut disokong melalui pengiraan yang dibuat oleh pengkaji berdasarkan rekod kehadiran atas talian bagi latihan-latihan yang dilaksanakan. Maka, pemilihan sampel kajian adalah berdasarkan formula Taro Yamanae (1967). Saiz sampel kajian yang digunakan dalam kajian ini adalah nisbah 0.5 yang mewakili aras keyakinan (e) iaitu sebanyak 210 peserta latihan secara atas talian.

Data-data yang diperoleh ini dianalisis menggunakan analisis deskriptif frekuensi iaitu peratusan, kekerapan dan min. Selain itu, analisis yang digunakan adalah analisis Chi Square, Cross-Tabulation dan analisis kolerasi. Analisis yang dilaksanakan ini kemudian dipersembahkan dalam bentuk dan kaedah yang sesuai.

\section{Hasil Kajian}

Jadual 1 menunjukkan dapatan kajian bagi profil responden yang dipilih semasa pengedaran borang soal selidik secara atas talian dan telah dianalisis. Dalam kajian ini, responden yang dipilih adalah peserta latihan secara atas talian di Kementerian Pertahanan, Malaysia. Maka, jadual di bawah merupakan hasil dapatan yang merangkumi profil responden iaitu umur, jantina, status perkahwinan, agama, taraf pendidikan, tempat tinggal, bahagian tugas dan pendapatan bulanan. Secara ringkasan, kebanyakan responden dalam kajian ini adalah responden lelaki iaitu seramai 123 orang responden yang berumur lingkungan 36 hingga 45 tahun. Selain itu, hampir keseluruhan responden telah berkahwin iaitu sebanyak 129 orang. Dari aspek agama responden pula, rata-rata responden adalah beragama Islam sebanyak 93 orang. Dalam aspek taraf pendidikan responden, majoriti peserta mempunyai taraf pendidikan kelompok SPM dan diploma iaitu seramai 74 orang. Berdasarkan dapatan bagi tempat tinggal responden, kebanyakan responden adalah yang tinggal berdekatan dengan Kementerian Pertahanan, Malaysia. Bilangan responden paling tinggi adalah dalam kalangan kakitangan yang tinggal di sekitar Setiawangsa sebanyak 60 orang daripada jumlah keseluruhan responden. Selain itu, dari segi bahagian tugas, majoriti responden merupakan kelompok kakitangan di Bahagian Pengurusan Sumber Manusia (BPSM), Bahagian Pengurusan Maklumat (BPM), Bahagian Kewangan (BK), Bahagian Akaun dan Bahagian Khidmat Pengurusan (BKP) iaitu seramai 60 orang. Akhir sekali, pendapatan bulanan bagi kebanyakan responden pula adalah antara RM 1001 hingga RM 2000.

Jadual 1: Profil responden

\begin{tabular}{lc}
\hline Profil Responden & \\
\hline Jantina & 123 \\
Lelaki & 87 \\
Perempuan &
\end{tabular}


Umur

18 hingga 25 tahun $\quad 39$

26 hingga 35 tahun $\quad 48$

36 hingga 45 tahun 63

46 hingga 55 tahun 48

56 dan ke atas $\quad 12$

Agama

Islam 93

Kristian $\quad 54$

Hindu $\quad 37$

Buddha 26

Status

Sudah berkahwin 129

Bujang 81'

$\begin{array}{ll}\text { Tahap pendidikan } & \\ \text { Ijazah dan keatas } & 59\end{array}$

Diploma/STPM dan setaraf $\quad 74$

SPM/SPMV dan setaraf $\quad 74$

PMR 3

Bahagian/Cawangan

BADSA/BUU/BP/BDPS/BIP 51

BPSM/BPM/BK/BA/BKP 60

JKHP/JHEV/MIDAS 42

UKS/UKPI/STRIDE 33

Lain-lain 24

Pendapatan bulanan
RM 1001 hingga RM 2000

RM 20001 hingga RM 3000

RM 3001 hingga RM 4000

Tempat tinggal

Wangsamaju $\quad 6$

Sri Rampai 6

Setiawangsa 60

Taman Dato' Keramat 39

Setapak 24

Titiwangsa 9

Ampang 27

Daerah di Selangor 33

Lain-lain 6

Sumber: Analisis berdasarkan SPSS

\section{Profil peserta latihan terhadap penyertaan latihan secara atas talian}

Berdasarkan hasil kajian yang diperoleh, profil kehadiran peserta menyertai latihan secara atas talian adalah berbeza-beza. Penyertaan utama latihan secara atas talian dalam kalangan kakitangan di kementerian ini secara majoriti adalah untuk mencukupkan jumlah hari latihan sebagai syarat wajib menjalani latihan dalam organisasi di mana mencatatkan peratusan tertinggi iaitu sebanyak 37.1 peratus. Berdasarkan pemerhatian pengkaji, pelaksanaan latihan secara atas talian telah menjadi pilihan utama setiap kakitangan untuk menyertai latihan mendepani pandemik COVID-19 berbanding menyertai latihan secara konvensional. Hal ini demikian kerana, kegusaran peserta terhadap penularan wabak yang semakin membimbangkan. Selain itu, bagi profil kekerapan penyertaan latihan secara atas talian pula menunjukkan, kebanyakan responden telah menyertai latihan sebanyak 4 kali dalam tempoh tersebut bersamaan 27.1 peratus. Hal ini disebabkan, kebanyakan responden lebih mudah untuk mengakses latihan secara atas talian seperti penggunaan platform ringan 'Facebook Live' dan 'Webinar'. Maka, platform latihan yang mudah untuk diakses tanpa memerlukan peralatan komputer riba dan telefon bimbit yang terlalu canggih amat memberi galakan kepada peserta untuk menyertai latihan secara atas 
talian di samping pemilihan nama latihan yang bersesuaian untuk menarik minat peserta. Sementelahan itu, dilihat daripada aspek lokasi peserta yang menyertai latihan secara atas talian, hampir keseluruhan responden mengakses dari rumah kerana kesesuaian masa latihan, persekitaran yang kondusif dan sokongan daripada ahli keluarga yang memberi galakan. Peratusan responden yang mengakses dari rumah sangat tinggi iaitu 80 peratus daripada jumlah keseluruhan responden. Selain itu, penggunaan alat bantuan latihan juga turut berbeza-beza mengikut cara responden menyertai latihan secara atas talian. Hasil kajian mendapati, kebanyakan responden memilih untuk menggunakan telefon pintar sebagai alat untuk menyertai latihan secara atas talian bersamaan 64.3 peratus. Selain faktor telefon pintar yang lebih mudah untuk mencapai talian internet yang stabil, faktor ini turut mempengaruhi responden kerana telefon pintar ketika ini berupaya untuk mengakses pelbagai aplikasi dan lebih praktikal berbanding komputer riba yang berat. Selain itu, terdapat beberapa faktor lain yang menjadi tarikan peserta untuk menyertai latihan secara atas talian. Menurut kajian ini, kesesuaian masa latihan atas talian yang fleksibel menunjukkan peratusan sebanyak 28.6 peratus. Menurut responden, masa untuk latihan bermula amat menepati masa kerana peserta tidak perlu untuk menunggu kehadiran penceramah yang lewat disebabkan kesesakan lalu lintas seperti yang sering berlaku apabila menghadiri latihan secara konvensional. Hal ini turut mempunyai signifikan dengan tujuan utama penyertaan peserta secara atas talian iaitu penceramah yang berkaliber.

Faktor penyertaan ulangan bagi majoriti responden adalah modul latihan yang bertepatan dengan skop kerja responden, bersesuian dengan isu terkini dan menarik. Faktor-faktor ini merujuk kepada ilmu selepas latihan (out-put) dapat diaplikasikan dengan baik selepas menyertai latihan tersebut. Majoriti responden seramai 58.6 peratus menyatakan rasa setuju dengan sebanyak 3.80 nilai min iaitu pada tahap yang tinggi. Tambahan pula, terdapat juga faktor lain terhadap penyertaan ulangan responden disebabkan oleh latihan yang dilaksanakan secara atas talian lebih interaktif sekaligus memberi pengalaman baharu menyertai latihan secara atas talian di mana responden menyatakan setuju dengan nilai persamaan 66.7 peratus. Malah, berdasarkan nilai min tersebut menunjukkan nilai min yang tinggi bersamaan 4.01. Bertepatan dengan kajian yang dilaksanakan oleh Arawati (2015), modul latihan yang memfokuskan bidang tugas pekerja akan menarik minat pekerja untuk mengambil bahagian dalam latihan yang dijalankan oleh organisasi. Penyataan ini juga disokong oleh Iqbal (2018) yang menyatakan, daya tarikan sesebuah modul latihan bukan sahaja terletak pada teknik penyampaian penceramah semata-mata, bahkan modul latihan perlu sesuai dengan bidang tugas, jantina, latar belakang dan umur pekerja. Hasil kajian mendapati, faktor rakaman video latihan secara atas talian yang boleh diulang tayang juga menjadi faktor penyertaan ulangan pekerja bersamaan 61.4 peratus responden yang menyatakan setuju dengan nilai min iaitu 3.84 sekaligus mencatatkan tahap yang tinggi. Faktor seterusnya adalah dasar sukarela responden yang menjadikan latihan sebagai tempat untuk menimba ilmu baharu yang belum pernah disertai untuk disumbangkan kepada organisasi dan dunia luar. Majoriti responden amat bersetuju yang mewakili 45.7 peratus dengan nilai min sebanyak 3.67 yang menunjukkan tahap yang tinggi. Menurut Taylor et al. (2019), pelaksanaan latihan yang pelbagai disiplin ilmu, seseorang itu dapat mempelajari ilmu baharu untuk menambah pengetahuan bekerja dan dapat menyumbangkan ilmu tersebut dalam kehidupan harian. Malah, mempelajari ilmu baharu ditempat kerja merupakan salah satu daya usaha kerajaan untuk melahirkan pekerja yang mempunyai pelbagai kemahiran dan ilmu pengetahuan di luar bidang tugas hakiki selaras dengan dasar industri 4.0.

\section{Perbincangan Kajian}

\section{Tahap kepuasan pekerja terhadap latihan secara atas talian mendepani pandemik COVID-19}

Pengurusan latihan secara atas talian yang dimaksudkan adalah terdiri daripada item-item yang merangkumi 17 komponen daripada strategi latihan yang berkesan iaitu strategi luaran dan strategi dalaman (Jadual 2). Strategi luaran ditakrifkan sebagai spesifikasi dan perincian latihan yang menyebabkan organisasi perlu mengenal pasti bidang-bidang baharu, pengetahuan, pemahaman dan kemahiran yang diperlukan untuk menangani sesuatu perubahan. Manakala strategi dalaman merujuk kepada langkah-langkah dalam pelaksanaan latihan untuk memperoleh impak terhadap perkembangan prestasi peserta. 
Berdasarkan Jadual 2, terdapat item-item yang menunjukkan tahap kepuasan responden berada pada tahap yang tinggi iaitu strategi luaran, kemudahan untuk mengakses platform atas talian dan modul latihan yang bertepatan dengan skop kerja, isu terkini serta menarik. Rata-rata responden amat berpuas hati dengan strategi luaran kerana pihak Cawangan Latihan telah mengatur dan mengiklankan setiap tentatif latihan yang dijalankan secara atas talian di mana nilai min adalah 3.81. Hal ini demikian kerana, pengiklanan setiap tentatif latihan yang akan dijalankan adalah teknik publisiti yang terbaik dalam menyampaikan maklumat dalam kalangan pekerja (Han, 2019). Kemudahan untuk mengakses platform secara atas talian menunjukkan pada tahap kepuasan yang tinggi iaitu nilai sebanyak 3.86. Pemilihan platform yang ringan dan tidak memerlukan pendaftaran yang sukar dapat memudahkan peserta untuk mengakses dengan lebih mudah dengan menggunakan telefon pintar. Di samping itu, hasil analisis turut menunjukkan tahap kepuasan responden berada pada tahap yang tinggi bagi modul latihan yang bertepatan dengan skop kerja, isu terkini dan menarik di mana nilai min adalah 3.70. Berdasarkan pemerhatian pengkaji, elemen ini memberi tanggapan pertama (first impression) terhadap minat peserta sebelum latihan disertai. Latihan yang bertepatan dengan skop kerja, berkaitan isu terkini dan menarik bukan sahaja dapat merangsang minat pekerja untuk menajamkan kemahiran diri, malah dapat menggalakkan pencapaian matlamat dalam organisasi.

Hasil kajian yang telah dilaksanakan menunjukkan, terdapat beberapa elemen yang perlu diambil langkah proaktif memandangkan terdapat dua item yang menunjukkan tahap kepuasan peserta latihan secara atas talian yang berada pada tahap yang rendah. Elemen ini merangkumi penyampaian penceramah yang statik dan kekurangan aktiviti lanjutan selepas slot latihan tamat. Bagi penyampaian penceramah, majoriti responden menyatakan tidak berpuas hati di mana nilai min adalah 2.33 . Hal ini demikian kerana, teknik penyampaian penceramah yang statik dan tidak pelbagai menyebabkan peserta menjadi hilang fokus. Penyampai penceramah yang serius lebih terarah kepada penyampai ilmu sematamata dan kurang menyelitkan unsur humor untuk menarik minat pendengar. Manakala, tahap kepuasan peserta yang menunjukkan nilai min yang paling rendah adalah tahap kekurangan aktiviti lanjutan selepas slot latihan tamat. Hal ini menyebabkan peserta kurang memahami kandungan latihan secara atas talian kerana urus setia tidak menyediakan aktiviti lanjutan seperti kuiz dan penilaian. Kefahaman kendiri juga tidak dapat dinilai secara holistik kerana tiada aspek penilaian dan ukuran yang dilakukan selepas slot latihan tamat. Oleh yang demikian, rata-rata responden yang menyertai latihan secara atas talian menyuarakan ketidakpuasan hati terhadap isu kekurangan aktiviti lanjutan selepas slot latihan.

Jadual 2: Tahap kepuasan pekerja terhadap latihan secara atas talian

\begin{tabular}{lll}
\hline Item & Min & Tahap \\
\hline Persekitaran di rumah & 3.66 & Sederhana \\
Kefahaman selepas latihan atas talian & 2.60 & Sederhana \\
Interaksi bersama penceramah & 2.49 & Sederhana \\
Kredibiliti penceramah & 2.99 & Sederhana \\
Pengiklanan dan info berkaitan latihan & 3.81 & Tinggi \\
Kemudahan mengakses platform & 3.86 & Tinggi \\
Latihan yang interaktif & 2.94 & Sederhana \\
Kemudahan merekod latihan & 2.86 & Sederhana \\
Penyampaian penceramah & 2.33 & Rendah \\
Gangguan teknikal & 3.01 & Sederhana \\
Penambahbaikan pengurusan & 3.34 & Sederhana \\
Kemahiran menggunakan teknologi & 3.17 & Sederhana \\
Kesesuaian modul latihan terhadap tugas & 3.70 & Tinggi \\
Sokongan berkaitan ICT & 2.80 & Sederhana \\
Aktiviti lanjutan selepas latihan & 1.80 & Rendah \\
Masa yang fleksibel & 2.39 & Sederhana \\
Penyediaan bahan sebelum latihan & 3.33 & Sederhana \\
Min keseluruhan & 3.00 & Sederhana \\
\hline
\end{tabular}


Berdasarkan hasil kajian melalui analisis Cross Tabulation dan Chi Square terhadap beberapa item yang telah dipilih oleh pengkaji, terdapat item-item yang menunjukkan hubungan yang signifikan terhadap pemboleh ubah umur. Item ini adalah alat bantuan latihan, lokasi peserta mengakses latihan dan kesesuaian modul latihan secara atas talian terhadap bidang tugas pekerja. Hasil analisis bagi item-item ini membuktikan bahawa, terdapat hubungan yang signifikan di mana nilai signifikan adalah lebih kecil berbanding nilai signifikan yang digunakan $(\mathrm{p}<.0 .5)$ iaitu nilai signifikan bagi setiap item ialah 0.003 , 0.013 dan 0.045 . Oleh yang demikian, hasil analisis menunjukkan terdapat hubungan signifikan antara item yang dipilih dengan pemboleh ubah umur. Seterusnya, analisis kolerasi (r) turut digunakan untuk menganalisis kekuatan antara hubungan tahap kepuasan peserta latihan secara atas talian mendepani pandemik COVID-19 dengan faktor penyertaan ulangan peserta latihan secara atas talian. Analisis menunjukkan, terdapat hubungan yang signifikan bagi item-item yang dipilih. Namun begitu, kekuatan antara kolerasi adalah sederhana.

Secara keseluruhannya, berdasarkan objektif kedua kajian menunjukkan bahawa, pengurusan latihan secara atas talian mendepani pandemik COVID-19 di Kementerian Pertahanan, Malaysia masih berada pada tahap yang sederhana dengan nilai min 3.00. Tahap kepuasan peserta yang menyertai latihan secara atas talian amat penting dalam mempengaruhi kuantiti peserta yang menyertai khususnya terhadap pembentukan impak prestasi pekerja pada masa hadapan. Hal ini demikian kerana, peserta yang berpuas hati dengan mutu latihan secara atas talian akan menggalakkan lagi penggunaan ICT dalam kalangan pekerja terhadap menyampaikan ilmu dan peningkatan prestasi.

\section{Cadangan langkah penambahbaikan terhadap pengurusan latihan secara atas talian di sektor awam}

Keseluruhannya, cadangan penambahbaikan yang diutarakan oleh responden merangkumi penambahbaikan strategi dalaman dan strategi luaran dalam pengurusan latihan di Kementerian Pertahanan, Malaysia. Hal ini disebabkan, pengurusan latihan yang efisyen dan sistematik akan mempengaruhi latihan yang dijalankan merangkumi semua aspek (Pagnini et al., 2019). Selain tu, cadangan ini juga menyentuh beberapa peranan pihak iaitu Cawangan Latihan, Bahagian Pengurusan Sumber Manusia (BPSM), kakitangan dan pihak kerajaan.

Kebanyakan responden yang menyertai latihan secara atas talian menyatakan keperluan untuk memperbanyakkan penambahbaikan dari aspek strategi luaran. Hal ini demikian kerana, aspek pengurusan dan penyediaan latihan secara atas talian yang dilaksanakan di Kementerian Pertahanan, Malaysia belum mencapai tahap yang sepatutnya semasa mendepani situasi sukar COVID-19. Antaranya, kekurangan aktiviti lanjutan selepas tamat latihan secara atas talian. Impaknya, peserta tidak dapat mengetahui tahap kefahaman diri selepas menyertai latihan tersebut kerana tiada aktiviti yang dilakukan seperti kuiz, penilaian kendiri dan sebagainya. Maka, pihak Cawangan Latihan perlu melalukan aktiviti lanjutan agar peserta dapat menilai tahap kefahaman masing-masing. Selain itu, pengkaji berpendapat bahawa aktiviti selepas latihan secara atas talian wajar dilaksanakan seperti kuiz berdasarkan topik yang dijalankan. Ini bermaksud, kedatangan peserta latihan secara atas talian diambil berdasarkan markah kuiz. Berdasarkan cara ini, peserta akan lebih fokus terhadap isi latihan dan dapat mengelakkan peserta mengisi kehadiran tetapi tidak menyertainya.

Seterusnya, para responden juga memberi idea terhadap pemilihan penceramah yang mempunyai daya penyampaian yang menarik khususnya cara penyampaian di alam maya. Daya penyampaian penceramah yang menarik berupaya memberi impak kepada penerimaan peserta terhadap ilmu yang diajar (Noor Azmi, 2015). Malah, penggunaan platform yang seragam dan khas perlu digunakan secara konsisten. Pihak Cawangan Latihan perlu mengkaji secara menyeluruh terhadap platform yang bersesuaian. Bagi sesetengah responden, jika kali pertama mereka menggunakan platform 'Webinar' untuk menyertai latihan, maka latihan yang menggunakan selain platform 'Webinar' akan mempengaruhi minat untuk disertai. Selain itu, penyediaan bahan latihan secara atas talian perlu diberikan lebih awal agar peserta dapat mengulang kaji kandungan yang akan diajar. Dilihat dari perspektif berbeza, terdapat responden yang menyatakan agar latihan yang dijalankan secara atas talian perlu dikategorikan mengikut kelas umur. Kesukaran peserta latihan yang berumur 40 tahun ke atas memerlukan bimbingan khas bagi kelancaran mengendalikan platform tersebut. 
Selain dari aspek penambahbaikan terhadap faktor yang sedia ada, responden-responden mencadangkan agar memperbanyakkan aktiviti perbincangan secara atas talian antara kakitangan dengan pihak kaunselor (supported team) agar dapat mendalami masalah, kekangan dan isu yang dihadapi oleh pekerja ketika mendepani pandemik COVID-19 terhadap prestasi diri semasa dan sebagainya. Selain itu, cadangan bahawa peralatan komputer yang sedia ada di pejabat, wajar dinaiktarafkan dengan meletakkan kamera (webcam) agar bagi pekerja yang memerlukan peralatan yang lebih canggih dan inginkan suasana yang lebih kondusif untuk menyertai latihan secara atas talian, boleh menggunakan peralatan di pejabat. Malah, waktu latihan secara atas talian juga perlu lebih fleksibel dengan had masa maksimum selama 2 jam.

Namun begitu, usaha yang dilaksanakan oleh pihak Cawangan Latihan dalam mencapai pengurusan latihan yang baik tidak mampu dicapai tanpa sokongan dan kerjasama daripada setiap kakitangan. Maka, kakitangan di sektor kerajaan amnya, kakitangan di Kementerian Pertahanan, Malaysia khasnya hendaklah mempraktikkan sikap yang positif dengan menyertai latihan yang dijalankan atas dasar untuk meningkatkan ilmu pengetahuan dengan ikhlas dan bertanggungjawab. Selain itu, penyertaan kakitangan dalam latihan ke arah meningkatkan matlamat mencapai objektif, misi dan visi organisasi perlu disahut agar dapat membentuk pekerja yang cakna terhadap peningkatan kemahiran kendiri.

Pihak kerajaan juga tidak terkecuali dalam menitikberatkan kepentingan menjalani latihan secara atas talian. Melalui kelonggaran kepada pekerja yang ingin ke pejabat, pekerja dapat mengakses serta menggunakan peralatan di pejabat dan mendapatkan suasana yang kondusif. Tambahan pula, pihak kerajaan juga perlu menggesa syarikat telekomunikasi di negara ini agar meningkatkan keluasan capaian internet bagi setiap kawasan. Perkara ini amat bertepatan agar kemudahan untuk mengakses internet akan memudahkan setiap pekerja untuk menyertai latihan tanpa gangguan teknikal. Malah, mengurangkan harga jualan pelan data internet yang lebih bersesuaian perlu diberi perhatian oleh pihak kerajaan bagi kepentingan untuk menyertai latihan secara atas talian.

Oleh itu, pelbagai pihak perlu bekerjasama dan mengembleng tenaga bagi memastikan pengurusan latihan di Kementerian Pertahanan, Malaysia mengekalkan kualiti dan bertepatan dengan kehendak serta keperluan pekerja. Dengan melaksanakan latihan berdasarkan garis panduan latihan dalam perkhidmatan, diharapkan dapat memberi impak yang drastik terhadap pembangunan sumber manusia. Berdasarkan panduan tersebut, aspek-aspek yang penting seperti reka bentuk asas, perancangan, penyediaan modul dan pemantauan pengurusan latihan dapat mengikuti spesifikasi yang betul.

\section{Kesimpulan}

Secara kesimpulan, pengurusan latihan khususnya secara atas talian di setiap organisasi sangat penting supaya setiap pengisian modul yang disediakan bertepatan dengan keperluan dan kehendak pekerja terhadap prestasi. Justeru, dalam merangka dan mempraktikkan pengurusan latihan yang bersistematik, tahap kepuasan dan persepsi kakitangan amat penting untuk membina strategi yang efektif dan berupaya memberi tahap kepuasan tertinggi. Seterusnya, pengurusan latihan khususnya secara atas talian wajib meliputi kesemua aspek iaitu strategi dalaman dan strategi luaran. Hal ini demikian kerana, aspek-aspek tersebut dapat memberi kelancaran kepada peserta dan memudahkan pengurusan latihan bagi pihak penganjur. Berdasarkan kajian ini, pengkaji telah menghuraikan dan mencapai objektif-objektif dalam kajian. Umumnya, setiap maklum balas yang dinyatakan oleh responden-responden dalam kajian ini amat penting untuk dijadikan sebagai rujukan pada masa hadapan. Tahap kepuasan kakitangan secara tidak langsung akan mempengaruhi kuantiti penyertaan ulangan terhadap latihan yang bakal dijalankan. Justeru, cadangan dan maklum balas yang dinyatakan itu, pihak seperti Cawangan Latihan, Bahagian Pengurusan Sumber Manusia Kementerian Pertahanan, Malaysia perlu melaksanakan langkah yang signifikan agar tahap kepuasan pekerja dapat melepasi tahap yang sedia ada ke tahap kepuasan yang maksimum.

Dalam usaha untuk memperkasakan pengurusan latihan yang baik, perkara ini sekali gus dapat menarik lebih ramai kehadiran penyertaan dan memberi tanggapan yang positif terhadap usaha gigih yang dilakukan oleh pihak pengurusan Cawangan Latihan. Selaras dengan matlamat kajian, cadangan 
langkah penambahbaikan terhadap pengurusan latihan secara atas talian di kementerian ini perlu diberi perhatian agar penyediaan latihan yang dijalankan mengikut spesifikasi yang telah ditetapkan. Namun begitu, kewajipan untuk semua pihak memainkan peranan amat penting kerana untuk mendapatkan hasil yang terbaik bukan hanya bergantung kepada satu pihak semata-mata. Justeru, diharapkan agar negara kita mempunyai kekuatan sumber manusia bukan sekadar dari sektor kerajaan bahkan dari sektor swasta agar matlamat untuk menjadi negara yang terus berdaya saing seiring dengan Transformasi Nasional 2050 mendepani era globalisasi.

\section{Penghargaan}

Penghargaan kepada Geran TAP-K012925, Geran Penyelidikan FRGS/1/2019/SS07/UKM/02/2 kerana membiayai sebahagian daripada kajian ini.

\section{Rujukan}

Arawati, A, Rahmah, I. (2015). Pengaruh latihan ke atas pembezaan personel dalam pengurusan rantaian bekalan (SCM): Kajian kes syarikat pembuatan di Malaysia. Geografia-Malaysian Journal of Society and Space 10 (76 - 88)

Hald, K. S., \& Mouritsen, J. (2018). The evolution of performance measurement systems in a supply chain: A longitudinal case study on the role of interorganisational factors. International Journal of Production Economics, 205, 256-271.

Han, J., Sun, J.-M., \& Wang, H.-L. (2019). Do high performance work systems generate negative effects? How and when? Human Resource Management Review.

He, Y., Donnellan, M. B., \& Mendoza, A. M. (2019). Five-factor personality domains and job performance: A second order meta-analysis. Journal of Research in Personality, 82.

Helton, G. L., Cameron, K. L., Zifchock, R. A., Miller, E., Goss, D. L., Song, J., \& Neary, M. T. (2019). Association Between Running Shoe Characteristics and Lower Extremity Injuries in United

INTAN, 1978 https://www.intanbk.intan.my/iportal/en/about-intan

Iqbal, M. Z, \& AlSheikh, M. H. (2018). Factors affecting the transfer of training to the workplace after a faculty development programme: What do trainers think? J Taibah Univ Med Sci, 13(6), 552-556.

Mackay, M. M., Allen, J. A., \& Landis, R. S. (2017). Investigating the incremental validity of employee engagement in the prediction of employee effectiveness: A meta-analytic path analysis. Human Resource Management Review, 27(1), 108-120.

Noor Azmi, M.Z., Azman, I., Ahmad Azan, R., \& Nursaadatun Nisak, A. (2015) Program pembangunan pengurusan dan impaknya terhadap pemindahan latihan: Kes tentera darat Malaysia. Geografia-Malaysian Journal of Society and Space 10 (14 - 26)

Padlee, S. F., Reimers, V., Mokhlis, S., Anuar, M. M., \& Ahmad, A. (2019). Keep up the good work in research universities: An importance-performance analysis. Australasian Marketing Journal $(A M J)$.

Pagnini, F., Phillips, D., Bercovitz, K., \& Langer, E. (2019). Mindfulness and relaxation training for long duration spaceflight: Evidences from analog environments and military settings. Acta Astronautica, 165, 1-8.

Pfister, J. A., Jack, S. L., \& Darwin, S. N. (2017). Strategizing open innovation: How middle managers work with performance indicators. Scandinavian Journal of Management, 33(3), 139150.

Ronen, S., \& Zuroff, D. C. (2017). How does secure attachment affect job performance and job promotion? The role of social-rank behaviors. Journal of Vocational Behavior, 100, 137-148.

Rosniza Aznie, C.R, Mohd Azlan, A., Rozalini, R., Rosmiza, M.Z., Abdul Rahim, M.N., Mohd. Fuad, M.J., \& Novel, L. (2017). Potensi Tarikan Ekopelancongan Rekreasi di Taman Rekreasi Air Panas (TRAP) Sungai Klah, Perak. Geografia-Malaysian Journal of Society and Space, 8(7), 2032. 
DOI: https://doi.org/10.47405/mjssh.v6i1.605

Russell, Z. A., Steffensen, D. S., Ellen, B. P., Zhang, L., Bishoff, J. D., \& Ferris, G. R. (2018). High performance work practice implementation and employee impressions of line manager leadership. Human Resource Management Review, 28(3), 258-270.

Saliba de Oliveira, J. A., Cruz Basso, L. F., Kimura, H., \& Sobreiro, V. A. (2018). Innovation and financial performance of companies doing business in Brazil. International Journal of Innovation Studies, 2(4), 153-164.

Stirpe, L., \& Zárraga-Oberty, C. (2017). Are High-Performance Work Systems always a valuable retention tool? The roles of workforce feminization and flexible work arrangements. European Management Journal, 35(1), 128-136.

Taro Yamane. (1967). Elementary Sampling Theory. Englewood Cliffs, NJ: Prentice Hall.

Taylor, M. A., \& Bisson, J. B. (2019). Changes in cognitive function: Practical and theoretical considerations for training the aging workforce. Human Resource Management Review.

Van Thielen, T., Bauwens, R., Audenaert, M., Van Waeyenberg, T., \& Decramer, A. (2018). How to foster the well-being of police officers: The role of the employee performance management system. Eval Program Plann, 70, 90-98.

Yuen, K. F., Loh, H. S., Zhou, Q., \& Wong, Y. D. (2018). Determinants of job satisfaction and performance of seafarers. Transportation Research Part A: Policy and Practice, 110, 1-12. 